\title{
Selective and context-dependent effects of chemical stress across trophic levels at the basis of marine food webs
}

\author{
Christoph Mensens, ${ }^{1,2}$ Frederik De Laender, ${ }^{3}$ Colin R. Janssen, ${ }^{2}$ Frances Camille Rivera, ${ }^{1}$ \\ Koen Sabbe, ${ }^{4}$ and Marleen De Troch ${ }^{1,5}$ \\ ${ }^{1}$ Biology Department, Marine Biology, Ghent University, Krijgslaan 281 - S8, 9000 Ghent, Belgium
${ }^{2}$ Laboratory of Environmental Toxicology and Aquatic Ecology, Ghent University, Coupure Links 653, Building F, 9000 Ghent, Belgium \\ ${ }^{3}$ Research Unit in Environmental and Evolutionary Biology, Biology Department, Université de Namur, \\ Rue de Bruxelles 61, 5000 Namur, Belgium \\ ${ }^{4}$ Biology Department, Protistology and Aquatic Ecology, Ghent University, Krijgslaan 281 - S8, 9000 Ghent, Belgium
}

\begin{abstract}
Human activities increasingly impact the functioning of marine food webs, but anthropogenic stressors are seldom included in ecological study designs. Diet quality, as distinct from just diet quantity, has moreover rarely been highlighted in food web studies in a stress context. We measured the effects of metal and pesticide stress (copper and atrazine) on the contribution of a benthic intertidal diatom community to two processes that are key to the functioning of intertidal systems: biomass (diet quantity) and lipid (diet quality) production. We then examined if stressors affected diatom functioning by selectively targeting the species contributing most to functioning (selective stress effects) or by changing the species' functional contribution (context-dependent effects). Finally, we tested if stress-induced changes in diet quality altered the energy flow to the diatoms' main grazers (harpacticoid copepods). Diatom diet quantity was reduced by metal stress but not by low pesticide levels due to the presence of an atrazine-tolerant, mixotrophic species. Selective effects of the pesticide reduced diatom diet quality by $60 \%$ and $75 \%$ at low and high pesticide levels respectively, by shifting diatom community structure from dominance by lipid-rich species toward dominance by an atrazinetolerant, but lipid-poor, species. Context-dependent effects did not affect individual diatom lipid content at low levels of both stressors, but caused diatoms to lose $40 \%$ of their lipids at high copper stress. Stress-induced changes in diet quality predicted the energy flow from the diatoms to their copepod consumers, which lost half of their lipids when feeding on diatoms grown under low and high pesticide and high metal stress. Selective pesticide effects were a more important threat for trophic energy transfer than context-dependent effects of both stressors, with shifts in diatom community structure affecting the energy flow to their copepod grazers at stress levels where no changes in diatom lipid content were detected.
\end{abstract}

Key words: atrazine; chemical stress; copepods; copper; diatoms; energy flow; fatty acids; marine food webs.

\section{INTRODUCTION}

The impact of human activities on biological communities and their contribution to ecosystem functioning has become a central topic in ecological research (Halpern et al. 2008, Cardinale et al. 2012, Gamfeldt et al. 2015). Although conservation research is framed within the context of anthropogenic change, exposure to anthropogenic stressors however is rarely included in the design of studies focusing on biodiversity effects on ecosystem functioning (McMahon et al. 2012, De Laender et al. 2016).

Stress can affect ecosystem functioning by causing biodiversity loss in terms of species richness, as well as through changes in community structure, without necessarily causing species to go extinct (Hillebrand et al. 2008, Wittebolle et al. 2009, Mensens et al. 2015, De Laender et al. 2016). Selective stress effects on community structure (hereafter "selective stress effects"; Wittebolle et al. 2009) can influence ecosystem functioning if stressed communities are dominated by tolerant species with a low functional contribution (Larsen et al. 2005, Mensens et al. 2015). If the functionally

Manuscript received 18 April 2017; revised 1 November 2017; accepted 6 April 2018. Corresponding Editor: Stephen B. Baines.

${ }^{5}$ Corresponding author. E-mail: marleen.detroch@ugent.be most important species are also the most stress-tolerant, loss of functioning under stress will be limited (Radchuk et al. 2016). In addition, functioning in stressed communities can be altered by "context-dependent effects," i.e., changes in the species' functional contribution (Fox 2006, Fox and Harpole 2008, Tylianakis et al. 2008b, Hiddink et al. 2009). Contextdependent effects can arise from direct effects of the environmental drivers on the species' functional contribution (Fox and Harpole 2008; e.g., physiological stress; Schimel et al. 2007), as well as from environmental drivers altering species interactions (Fox 2006, Fox and Harpole 2008).

The majority of experiments designed to address ecosystem functioning under anthropogenic change have focused on single trophic levels, usually primary producers (Raffaelli 2006, Cardinale et al. 2011). Stressors that alter functioning at the producer level can however have concomitant impacts on their consumers (Rohr and Crumrine 2005, McMahon et al. 2012). In the frame of the subject of quantity of available food, some recent studies proposed methods to evaluate the abundance of trophic resources also according to the impacts of anthropogenic stressors (Zupo et al. 2017). Far less attention has been devoted to diet quality, which considers a diet's biochemical composition, for example lipid content (Jodice et al. 2006, Guo et al. 2016), and which strongly 
affects growth, reproduction and energy profiles of the consumers (Österblom et al. 2008, Taipale et al. 2013). The biochemical composition of primary producers is increasingly affected by human disturbance (Guo et al. 2016, SanperaCalbet et al. 2017), which has made the integration of food biochemistry into traditional studies of diet quantity a key challenge for estimating food web functioning under stress (Arts and Wainmann 1999, Guo et al. 2016).

Benthic diatoms are the main primary producers in many soft-sediment intertidal habitats, and diatom diet quality in terms of essential fatty acid (EFA) content plays a crucial role in trophic energy transfer (Arts et al. 2001, Taipale et al. 2013). EFAs cannot be synthesized by animals but are key determinants of the growth and energy content of aquatic consumers (Brett and Müller-Navarra 1997, von Elert 2002, Arendt et al. 2005, Litzow et al. 2006). Moreover, the oxidation of polyunsaturated C16- and C20-FAs (polyunsaturated Fas or PUFAs) to short-chain polyunsaturated aldehydes (PUAs; Miralto et al. 1999) and other non-volatile oxylipins (NVOs), such as hydroxy-fatty acids, epoxy-hydroxy-fatty acids, and oxo-acids (D'Ippolito et al. 2005) can cause deleterious effects of diatom diets for consumers. Here, we first measure the effects of metal and pesticide stress (copper and atrazine, see further) on the structure of a benthic diatom community, its biomass and its production of essential fatty acids, i.e., on the quantity and quality of the diatoms as a diet.

Next, we test if stressor-induced changes in EFA production in the diatom community were caused by selective or context-dependent stress effects. Context-dependent effects are measured by comparing EFA concentrations in experimental diatom communities with those in synthetic communities. The latter are computed for all control and stress treatments from the individual species' EFA production values in unstressed monocultures, and as such uniquely mimic the selective stress effects while excluding all contextdependent effects.

Harpacticoid copepods are among the main consumers of benthic diatoms and incorporate large amounts of EFAs from their algal diet, making them key players in the energy transfer from primary producers to higher trophic levels (Alheit and Scheibel 1982, Buffan-Dubau and Carman 2000, Andersen et al. 2005). Therefore, any potential change in grazer EFA content, due to context-dependent stress effects on diatom diet quality or due to selective effects leading to dominance of diatoms with high or low lipid content, could impact the energy flow in intertidal systems. Therefore, we test if changes in survival and EFA content of the harpacticoid copepod Microarthridion littorale, the dominant copepod species at the study site, are related to atrazine and copper effects on the quality of its diatom diet. Next to its dominance in the study area, this harpacticoid copepod is an efficient grazer on epipelic diatoms forming a biofilm on the intertidal sediment in the study site and is relatively easy to manipulate in lab experiments (De Troch et al. 2012b).

Atrazine is an herbicide that binds to the plastoquinone binding protein of photosystem II, disrupting photosynthetic electron flow (Legrand et al. 2006, Knauert 2008) and thus the growth and photosynthesis of aquatic primary producers, such as microalgae (Pennington et al. 2001, Larras et al. 2016). Atrazine is commonly not acutely toxic to aquatic consumers, but has adverse chronic effects on consumers due to food limitation, hormonal disruption, and reduced reproduction, although these reproductive and hormonal effects are not consistently observed (Hayes et al. 2011). Despite its Europe-wide ban in 2001, atrazine is still a common pollutant in European estuaries (Noppe et al. 2007) and remains one of the most-used pesticides worldwide (Benbrook 2016). In contrast to organic pesticides, heavy metals occur naturally in the environment, and several of them are essential for organism physiology (Hänsch and Mendel 2009). This is the case for copper, which is involved in several metabolic pathways in microalgae, as an essential micronutrient and component of proteins and enzymes (Hänsch and Mendel 2009). However, copper concentrations above the required levels are toxic to marine organisms at all trophic levels (Real et al. 2003, Manimaran et al. 2012). As copper enters coastal environments through river run-off, it affects both primary producers and consumers through the formation of reactive oxygen species (ROS), which can lead to cell death by damaging cell membranes and nucleic acids (Rhee et al. 2013). Copper also affects marine primary consumers by inhibiting membrane transport proteins (Bianchini et al. 2004) and by limiting the quantity of their algal diet (Pinho et al. 2007).

\section{Methods}

\section{Experimental organisms and culture conditions}

The harpacticoid copepod Microarthridion littorale (family Tachidiidae) was collected from intertidal mud at the polyhaline Paulina site in the Westerschelde estuary (southwest Netherlands, $51^{\circ} 21^{\prime} \mathrm{N}, 3^{\circ} 43^{\prime} \mathrm{E}$ ), where it represented the dominant grazer ( $\sim 90 \%$ of all harpacticoid individuals). $M$. littorale specimens were extracted alive from the sediment using a mixed technique of sediment decantation and extraction via white light attraction. Adult specimens were randomly collected with a glass Pasteur pipette using a Wild M5 binocular (Joint Stock Company, Heerbrugg, Switzerland). Copepods were washed three times over a $38-\mu \mathrm{m}$ sieve and placed in glass jars with filtered and autoclaved natural seawater (salinity $32 \pm 1 \mathrm{psu}$ ) overnight in order to empty their intestines prior to the start of the experiment.

The diatom community was composed of six species representing the most abundant genera (i.e., Nitzschia, Amphora, Cylindrotheca, Gyrosigma, and Navicula) observed at the sampling site (Appendix S1: Table S1). All diatom species were obtained from the Diatom Collection of the Belgian Coordinated Collection of Micro-organisms culture hosted at the Protistology and Aquatic Ecology Research Group (Ghent University, Ghent, Belgium). Prior to the experiments, the diatoms were grown in tissue bottles (CELLSTAR TC, $175 \mathrm{~cm}^{2}$ growth surface, CellStar, Greiner Bio-One, Frickenhausen, Germany) during $10 \mathrm{~d}$ in a climate room at $15^{\circ} \pm 1^{\circ} \mathrm{C}$, a light/dark cycle of $12 \mathrm{~h} / 12 \mathrm{~h}$ and an illumination of $90 \mu \mathrm{mol}$ photons $\cdot \mathrm{m}^{-2} \cdot \mathrm{s}^{-1}$, in culture medium consisting of filtered and autoclaved natural seawater (salinity $32 \pm 1$ psu) enriched with f/2 nutrients (Guillard 1975). In spite of their potentially different optimal requirements, applying the same conditions (e.g., in terms of irradiance) was found to be appropriate (see previous experiments of De Troch et al.) as the species also co-occur in the field. 


\section{Diatom experiments}

The experimental diatom communities were exposed to five treatments to 0, 200 (hereafter low), and 500 (hereafter high) $\mu \mathrm{g} / \mathrm{L}$ atrazine and copper, respectively. Concentrations were based on trial tests (data not shown) as well as published sensitivity data for marine benthic diatoms (Pistocchi et al. 1997, Levy et al. 2007, Wood et al. 2014). Atrazine treatments were prepared from a stock solution obtained by dissolving $50 \mathrm{mg}$ commercial atrazine (2-chloro-4-ethylamino-6-isopropylamino-s-triazine, $99.8 \%$ pure; SigmaAldrich Chemie Gmbh, Munich, Germany) in $10 \mathrm{~mL}$ acetone as a carrier to increase the solubility of atrazine, with a maximum final volume of $0.01 \%$ acetone in the treatments. An acetone control treatment of $0.01 \%$ acetone was included and compared to an acetone-free control to test for carrier effects. All atrazine treatments were compared to the acetone control. Copper (as a $\mathrm{Cu}[\mathrm{II}] \mathrm{Cl}_{2}$ solution, analytical grade; VWR International, Leuven, Belgium) was spiked directly into the culture medium before exposure of the diatoms. F/2 culture medium was prepared without EDTA, to avoid complexation of free copper ions (Pistocchi et al. 1997). The obtained atrazine and copper concentrations that were finally applied in the experiment are listed in Appendix S1: Table S2. Additionally, the six diatom species were grown in monoculture under control conditions, to quantify each species' biomass and EFA production in the absence of the stressors (Appendix S1: Table S1). All treatments were run in tissue culture flasks (CELLSTAR TC, $175 \mathrm{~cm}^{2}$ growth surface, CellStar, Greiner Bio-One), with nine replicates per treatment (three replicates in the monoculture treatments). Each microcosm $(100 \mathrm{~mL})$ was inoculated with a total cell density of approximately 5,000 diatom cells $/ \mathrm{mL}$ (belonging to the same species in the monocultures, between 800 and 850 cells $/ \mathrm{mL}$ per species in the diatom communities) from exponentially growing cultures, and incubated in a climate room at $15^{\circ} \pm 1{ }^{\circ} \mathrm{C}$, under a light:dark cycle of $12 \mathrm{~h}: 12 \mathrm{~h}$ at $90 \mu \mathrm{mol}$ photons $\cdot \mathrm{m}^{-2} \cdot \mathrm{s}^{-1}$. Culture medium was renewed after 8 and $15 \mathrm{~d}$. Diatom biofilms as food for the copepod experiment as well as for the EFA analyses (see EFA analyses) were harvested after $15 \mathrm{~d}$ (late exponential growth phase). The experiments were terminated after $25 \mathrm{~d}$.

Diatom biomass was quantified as biovolume after $0,2,5$, $10,15,20$, and $25 \mathrm{~d}$ of incubation. Biovolume was calculated from cell densities, linear dimensions (measured digitally using ImageJ; Schneider et al. 2012) and formulas representing the closest approximation of geometric shape for each genus (Hillebrand et al. 1999; Appendix S1: Table S1). Cell densities (in cells $/ \mathrm{mL}$ ) were determined by digitally counting the cells (ImageJ cell counting software) in photographs obtained by magnifying and photographing $(\times 100)$ an area of $0.66 \mathrm{~mm}^{2}$ per microcosm, using an inverted Axiovert 135 Zeiss microscope (Carl Zeiss, Jena, Germany) and a connected digital camera (Canon PowerShot G11, Canon, Diegem, Belgium). All analyses below use the biomass on day 15 .

Diatom biofilms from three replicates per treatment were harvested as food for the corresponding treatments in the copepod experiment (see copepod experiment), and purified from copper and atrazine by centrifugation at $50 \mathrm{~g}$ for $10 \mathrm{~min}$. The supernatant was replaced with $\mathrm{f} / 2$ culture medium, and the suspension was centrifuged again at $50 \mathrm{~g}$ for
$10 \mathrm{~min}$. A concentrated pellet containing $2.05 \mathrm{~mm}^{3}$ diatom biovolume per replicate was transferred to nine Eppendorf microtubes $\left(0.23 \mathrm{~mm}^{3}\right.$ per microtube), freeze-dried, and preserved at $-80^{\circ} \mathrm{C}$. The individual microtubes contained the food aliquot for each day of the respective treatments in the copepod experiment (see copepod experiment).

\section{Copepod experiment}

We tested the effect of diatom diet quality by offering $M$. littorale diatom diets of equal biomass under unstressed conditions. The copepod experiment consisted of five treatments, each with three replicates of $100 \mathrm{M}$. littorale copepods (a natural mix of adult males and [gravid] females), that were fed for $10 \mathrm{~d}$ an equal biomass of diatoms grown under unstressed conditions and low and high atrazine and copper stress, respectively. The experiment was conducted in glass jars containing $100 \mathrm{~mL}$ of filtered and autoclaved seawater in a climate room at $15^{\circ} \pm 1^{\circ} \mathrm{C}$ with a $12: 12 \mathrm{~h}$ light: dark cycle and $40-50 \mu \mathrm{mol}$ photons $\cdot \mathrm{m}^{-2} \cdot \mathrm{s}^{-1}$. To ensure a constant food supply, each treatment was inoculated with a concentrated diatom pellet of $0.23 \mathrm{~mm}^{3}$ biovolume every day, and unconsumed diatoms were removed from the bottom of the jars. Over the duration of the experiment, a total diatom biovolume of $2.05 \mathrm{~mm}^{3}$ was applied per experimental unit, corresponding to $3-5 \times 10^{6}$ diatom cells per treatment. At the end of each day, there was no food depletion in any of the treatments. Based on our previous experiments (De Troch et al. 2005, 2007), the provided quantity of diatoms can be considered as above the feeding saturation level. Copepod mortality was determined at the end of the experiment, and surviving (85-100\%) individuals from each experimental unit were washed in natural seawater to remove food particles, left $12 \mathrm{~h}$ to empty their gut, and stored at $-80^{\circ} \mathrm{C}$ for further fatty acid analysis.

\section{EFA analyses}

Essential fatty acids (EFAs) as a marker of diatom diet quality were quantified as the content of eicosapentaenoic

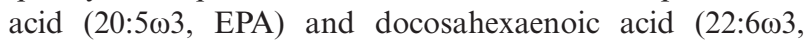
DHA). These EFAs were selected as proxies to quantify the energy transfer in view of their relevance for the next trophic level (copepods). Three replicates of $8 \mathrm{~mL}$ suspended diatom culture per treatment of the diatom communities and monocultures were collected after $15 \mathrm{~d}$. The samples were centrifuged for $10 \mathrm{~min}$ at $10^{\circ} \mathrm{C}$ at $50 \mathrm{~g}$. After undergoing the same purification process as the diatom food samples for the grazer experiment, pellets were resuspended, placed in a glass vial and stored at $-80^{\circ} \mathrm{C}$ for fatty acid analysis.

Copepod and diatom EFA content was measured through hydrolysis of total lipid extracts and methylation to FA methyl esters (FAME), followed by the analysis of the obtained FAME using a gas chromatograph (HP 6890N) coupled to a mass spectrometer (HP 5973) according to the protocol described in De Troch et al. (2012a) for copepods and Mensens et al. (2015) for diatoms. The quantification function of each individual FAME was obtained by linear regression of the chromatographic peak areas and corresponding known concentrations of the standards (ranging from 5 to $250 \mathrm{ng}$ / $\mathrm{mL}$ ). All EFA concentrations were standardized to diatom 
biomass (see diatom experiments) or the number of copepod individuals for diatoms and copepods, respectively.

\section{Data analysis}

An analysis of the diatom community structure among the treatments (control, low and high atrazine and copper) was conducted with a nonmetric multidimensional scaling method based on Bray-Curtis similarity. A one-way analysis of similarity (ANOSIM) was used to test for significant biomass differences between the treatments. Subsequently, percentages of similarity (SIMPER) were calculated to determine the main species contributing to any differences in community structure.

Differences in diatom biomass and EFA production among the treatments were tested with a generalized least squares model, with biomass and EFA production as response variables and treatment type as categorical predictor

$$
Y \sim \beta_{T} \times T
$$

where $Y$ is the response variable (biomass or EFA production per unit biomass), $T$ is the treatment type (control, low and high atrazine and copper), and the beta coefficient $\beta_{T}$ is the slope measuring the effect of the treatment type on biomass or EFA production. Biomass and EFA production among treatments were compared with pairwise Tukey's tests correcting $P$ values for multiple comparisons by the single-step method.

Next, we tested if potential changes in diatom EFA production were due to selective or context-dependent effects of atrazine and copper. Selective and context-dependent effects were quantified by comparing the EFA production in experimental and synthetic diatom communities. The synthetic communities have the same community structure as observed in the corresponding treatments of the experimental communities, but are computed from the EFA production in unstressed monocultures of each species (Eq. 2). The synthetic communities thus reflect the EFA production expected at the same community structure as induced by copper and atrazine, however without any stress exposure or species interactions.

$$
Y_{\mathrm{SYN}, j}=\frac{\sum_{i=1}^{N} M_{i, j=0} \times B_{i, j}}{B_{T, j}} .
$$

$Y_{\mathrm{SYN}_{2} j}$ is the EFA production per unit biomass in synthetic communities of the same structure as the experimental communities at atrazine or copper concentration $j . M_{i, j=0}$ is the mean EFA production per unit biomass of species $i$ in monoculture under unstressed conditions $(j=0) . B_{i, j}$ is the biomass of species $i$ observed in the experimental community at the stress level $j . B_{T, j}$ is the total biomass observed in the experimental community at stress level $j$.

Selective and context-dependent effects of both stressors were analysed with a generalized least squares model (Eq. 3) and pairwise comparisons of the EFA production in experimental and synthetic diatom communities

$$
Y \sim \beta_{T} \times T
$$

where $Y$ is the diatom EFA production per unit biomass, $T$ is the treatment type (control, low and high atrazine and copper in the experimental and synthetic diatom communities), and the beta coefficient $\beta_{T}$ is the slope measuring the effect of the treatment type on EFA production. Pairwise comparisons were performed with a Tukey's test correcting $P$ values for multiple comparisons by the single-step method.

Context-dependent effects occur when synthetic and experimental communities within the same treatment differ in their EFA production per unit biomass. Since both community types have the same structure, any differences in EFA between the two community types result from direct stress effects or species interactions in the experimental community. Consequently, any differences between experimental and synthetic communities of the same treatment point to context-dependent effects.

Selective stress effects occur when synthetic communities reflecting the control community structure differ in their EFA production from synthetic communities reflecting the community structure under stress. Since EFA values for synthetic communities are computed from those of unstressed monocultures, any differences between synthetic communities are related to differences in community structure rather than direct stress effects or species interactions. Consequently, any differences among synthetic communities are linked to selective rather than context-dependent effects. Appendix S1: Fig. S1 provides a scheme visualizing the quantification of context-dependent and selective stress effects.

The response of copepod fatty acid content to stressorinduced alterations in the quality and community structure of their diatom diet was analysed with generalized least squares models, with copepod fatty acid content as response variable and diatom diet quality and community structure as predictors (Eq. 4). Diatom diet quality was quantified as EFA production, diatom community structure as the BrayCurtis percent similarity to the average community structure in the controls (Eq. 5). Models were fitted separately for copepods feeding on atrazine- and copper-exposed diatoms respectively, to test if the effects of either stressor on copepod fatty acid content can be predicted from changes in diatom diet quality or community structure

$$
E_{\mathrm{C}} \sim a+b \times E_{\mathrm{D}}+c \times C_{\mathrm{D}}
$$

where $E_{\mathrm{C}}$ is the copepod fatty acid content (EFA content per copepod individual), $E_{\mathrm{D}}$ is diatom diet quality (EFA production per unit biomass), $C_{\mathrm{D}}$ is diatom community structure (see Eq. 5), $a$ is the intercept, and $b$ and $c$ represent the slopes, i.e., the relation of copepod EFA content to diatom diet quality and diatom community structure. If $E_{\mathrm{D}}$ and $C_{\mathrm{D}}$ were correlated (correlation factor $>0.5$ ), models were fitted separately for both predictors

$$
C_{\mathrm{D}}=100 \times \frac{1-\sum\left|B_{i, j}-\mu B_{i, j=0}\right|}{\sum\left(B_{i, j}+\mu B_{i, j=0}\right)}
$$

where $B_{i, j}$ is the biomass of species $i$ at the atrazine or copper concentration $j$ and $\mu B_{i, j=0}$ is the mean biomass of species $i$ in the control $(j=0)$. 
For all least squares model fits, normality and homogeneity of model residuals were inspected by evaluation of quantile-quantile plots and Shapiro-Wilk's test and by Levene's test and plotting residuals vs. explanatory variables, respectively. Untransformed data did not violate normality (Shapiro-Wilk's test, $\alpha>0.1$ ). If indications of deviations from normality were detected $(0.1<\alpha<0.15)$, an optimal BoxCox transformation was applied to maximize normality of model residuals (Box and Cox 1964, Venables and Ripley 2002). If homogeneity was violated, the model was refitted using an exponential variance structure allowing residuals to change with the continuous predictor $X$ (weights $=$ varExp (form $\sim 1 \mid X$ ) or allowing different variances according to the categorical predictor $\mathrm{P}$ (weights $=$ varIdent $($ form $\sim 1 \mid \mathrm{P})$. By means of likelihood ratio testing, the significance of these structures was tested $(\alpha=0.05)$.

Multivariate, ANOSIM, and SIMPER analyses of diatom community structure were performed using Primer 6 software (Clarke and Gorley 2006). All other calculations were done in R 3.0.1. using RStudio (R Development Core Team 2016). The package nlme (Pinheiro et al. 2016) was used for the fitting of generalized least squares models and optional variance structures. Optimal Box-Cox transformations were performed using MASS (Venables and Ripley 2002). Pairwise Tukey's tests on the fitted models were performed with the package multcomp (Hothorn et al. 2008), using the general linear hypothesis test (glht) function, correcting $P$ values for multiple comparisons by the single-step method (default procedure in multcomp).

\section{RESULTS}

\section{Diatom community structure}

The structure of diatom communities under atrazine differed from the structure of communities grown under control conditions and copper exposure (see nonmetric multidimensional scaling in Appendix S1: Fig. S2, ANOSIM global $R=0.833, P=0.001)$. The community structure at both copper levels resembled the community structure observed under control conditions (14\% and 18\% dissimilarity, respectively), with $N$. acicularis and $N$. arenaria contributing most to biomass in both types of communities (Fig. 1; Appendix S1: Table S3). In contrast, both atrazine levels induced a change in community structure $(70 \%$ and $76 \%$ dissimilarity from the control, Appendix S1: Table S3) due to an increase in biomass of $C$. closterium, which compared to the control showed a 6- and 12-fold increase in biomass in the high and low atrazine treatments, respectively. This resulted in a dominance by C. closterium in the atrazine-exposed communities, as it contributed more than $70 \%$ of the total biomass at both atrazine levels (Fig. 1; Appendix S1: Table S4). Within the control, copper, and atrazine treatments, the community structure of diatom communities showed little variance (within-treatment similarities between $84 \%$ and $92 \%$; Appendix S1: Table S4).

\section{Diatom biomass and EFA production}

Diatom biomass and EFA production changed depending on treatment type (all $P<0.0001$, Figs. 1, 2). The post-hoc analyses showed that diatom biomass was reduced at both

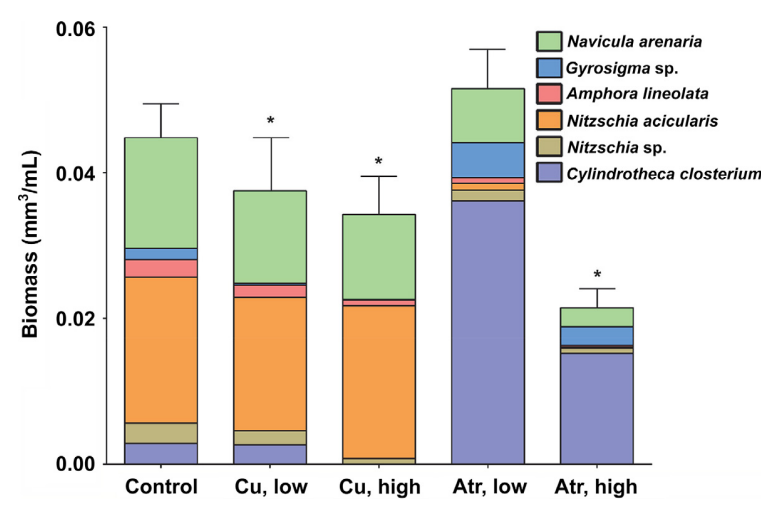

FIG. 1. Total biomass production per treatment and biomass of the component species for diatom communities grown in control, low $(200 \mu \mathrm{g} / \mathrm{L})$ and high $(500 \mu \mathrm{g} / \mathrm{L})$ atrazine (Atr) and copper $(\mathrm{Cu})$ treatments. Significant differences $(P \leq 0.05)$ in biomass production from the control are indicated with asterisks (*). Bars show mean biomass, error bars are the standard deviation.

low and high copper as well as at high but not at low atrazine concentrations (Fig. 1, Table 1). Diatom EFA production was reduced at both levels of atrazine, but only at high copper stress (Fig. 2, gray bars, Table 1). High copper stress reduced the EFA production of diatom communities by $40 \%$, low and high atrazine stress by $60 \%$ and $75 \%$, respectively (gray bars in Fig. 2).

\section{Selective and context-dependent stress effects on diatom EFA production}

The EFA production in the experimental and synthetic diatom communities changed depending on treatment type

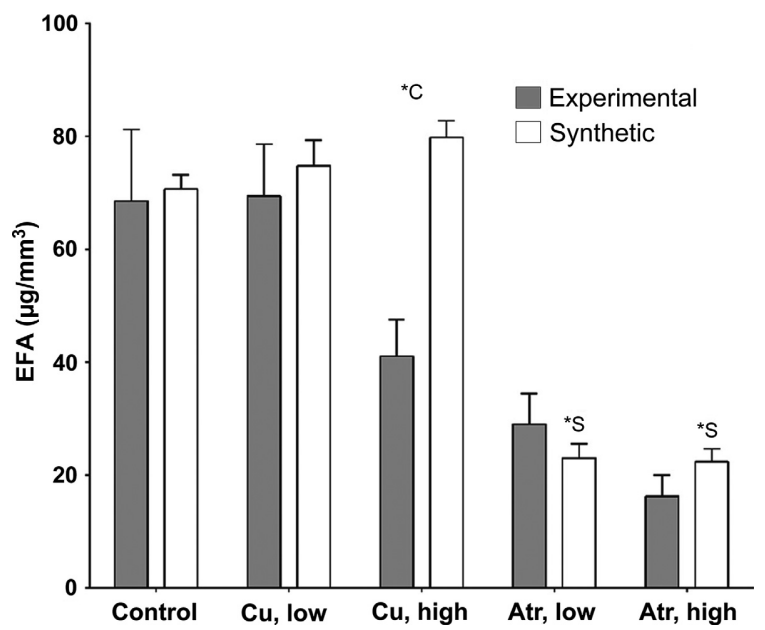

FIG. 2. Atrazine and copper effects on diatom diet quality (EFA production). Experimental communities were grown in control, low $(200 \mu \mathrm{g} / \mathrm{L})$ and high $(500 \mu \mathrm{g} / \mathrm{L})$ atrazine $(\mathrm{Atr})$ and copper $(\mathrm{Cu})$ treatments. Synthetic communities were computed from unstressed monocultures in the same community structure observed at each stress level. Significant differences $(P \leq 0.05)$ in EFA production indicating selective and context-dependent stress effects are indicated with asterisks $(*)$. ${ }^{*} \mathrm{C}$ indicates pairwise differences among stressed and synthetic communities of the same structure (context-dependent stress effects). *S indicates pairwise differences among control and stress treatments within the synthetic communities (selective stress effects). Values are mean EFA concentrations and bars are the standard deviation. 
TABLE 1. Pairwise comparisons of biomass and EFA production in diatom communities as estimated by generalized least squares model fits.

\begin{tabular}{|c|c|c|c|c|c|c|}
\hline Treatment & Treatment & Est & lwr & upr & $z$ & $P$ \\
\hline \multicolumn{7}{|l|}{ Biomass } \\
\hline Control & Atr, low & -6.756 & -9.18 & -4.33 & 2.78 & 0.059 \\
\hline Control & Atr, high & 23.327 & 20.90 & 25.75 & 9.61 & $<0.001$ \\
\hline Control & $\mathrm{Cu}$, low & 7.273 & 4.85 & 9.70 & -3.00 & 0.036 \\
\hline Control & $\mathrm{Cu}$, high & 10.533 & 8.11 & 12.96 & 4.34 & $<0.001$ \\
\hline Atr, low & Atr, high & 30.083 & 27.66 & 32.51 & 12.39 & $<0.001$ \\
\hline $\mathrm{Cu}$, low & $\mathrm{Cu}$, high & 3.260 & 0.83 & 5.69 & 1.34 & 0.666 \\
\hline \multicolumn{7}{|c|}{ EFA production } \\
\hline Control & Atr, low & 2.143 & 1.30 & 2.99 & 8.00 & $<0.001$ \\
\hline Control & Atr, high & 3.191 & 2.34 & 4.04 & 12.08 & $<0.001$ \\
\hline Control & $\mathrm{Cu}$, low & -0.046 & -0.89 & 0.80 & -0.17 & 1.000 \\
\hline Control & $\mathrm{Cu}$, high & 1.372 & 0.52 & 2.22 & 5.12 & $<0.001$ \\
\hline Atr, low & Atr, high & 0.317 & 0.13 & 0.51 & 5.72 & $<0.001$ \\
\hline $\mathrm{Cu}$, low & $\mathrm{Cu}$, high & 0.305 & 0.11 & 0.50 & 4.91 & $<0.001$ \\
\hline
\end{tabular}

Notes: Biomass or EFA production indicate to which response variable models were fitted. "Treatment" (low [200 $\mu \mathrm{g} / \mathrm{L}]$ and high $[500 \mu \mathrm{g} / \mathrm{L}]$ atrazine $[\mathrm{Atr}]$ and copper [Cu]) indicates which treatments are compared. "Est" indicates the difference in biomass (in $10^{3} \mathrm{~mm}^{3} /$ $\mathrm{mL}$ ), and EFA (in $\mu \mathrm{g} / \mathrm{mm}^{3}$ ) production between the compared treatments as estimated by generalized least squares models fitted to untransformed biomass and Box-Cox transformed EFA data, "lwr" and "upr" indicate the lower and upper confidence intervals of the estimated difference. The $z$ and $P$ values corrected for multiple comparisons by the single-step method are presented; values in boldface type are statistically significant $(P \leq 0.05)$.

(both $P<0.0001)$. Pairwise comparisons of the EFA production in experimental and synthetic communities did not show differences among the two community types in the control and low copper treatments (Fig. 2, Table 2). At high copper stress, the EFA production in the experimental community was lower than in the corresponding synthetic community (Fig. 2, Table 2). The EFA loss induced by high copper stress in experimental communities was thus not reflected in unstressed synthetic communities of the same structure, whose EFA production did not differ from the control (Fig. 2, Table 2).

In the atrazine treatments, both the experimental and synthetic communities had a lower EFA production than the control (Fig. 2, Table 2). Within each atrazine treatment, the EFA production of experimental and synthetic communities did not differ (Fig. 2, Table 2). The EFA loss induced by atrazine in the experimental communities was thus reflected by the synthetic communities, which mimicked the community structure under atrazine without actual exposure to the herbicide (Fig. 2, Table 2).

\section{Diet quality effect on copepods}

The EFA content of $M$. littorale was related to the stressorinduced changes in diatom diet quality (both stressors) and diatom community structure (atrazine only; Fig. 3, Table 3). Copepods maintained their control EFA content when feeding on diatoms from the low copper treatment, but lost half of their EFAs when feeding on diatoms grown under high copper stress (Fig. 3). This resulted in a positive correlation of copepod EFA content and diatom EFA content (Table 3). When offered diatoms from the low and high atrazine treatments,

TABLE 2. Pairwise comparisons of EFA production in treatments of experimental and synthetic diatom communities as estimated by generalized least squares model fits.

\begin{tabular}{|c|c|c|c|c|c|c|c|c|c|}
\hline Effect & Com & Treatment & Com & Treatment & Est & lwr & upr & $Z$ & $P$ \\
\hline SE & syn & control & syn & Atr, low & 2.695 & 1.85 & 3.54 & 10.06 & $<0.001$ \\
\hline SE & syn & control & syn & Atr, high & 2.746 & 1.90 & 3.60 & 10.25 & $<0.001$ \\
\hline SE & syn & control & syn & $\mathrm{Cu}$, low & -0.173 & -1.02 & 0.67 & -0.65 & 0.999 \\
\hline SE & syn & control & syn & $\mathrm{Cu}$, high & -0.381 & -1.23 & 0.47 & -1.42 & 0.921 \\
\hline $\mathrm{CD}$ & $\exp$ & control & syn & control & -0.110 & -0.96 & 0.74 & 0.41 & 1.000 \\
\hline $\mathrm{CD}$ & $\exp$ & Atr, low & syn & Atr, low & 0.442 & -0.41 & 1.29 & 1.65 & 0.823 \\
\hline $\mathrm{CD}$ & $\exp$ & Atr, high & syn & Atr, high & -0.554 & -1.40 & 0.29 & -2.07 & 0.550 \\
\hline $\mathrm{CD}$ & $\exp$ & $\mathrm{Cu}$, low & syn & $\mathrm{Cu}$, low & -0.237 & -1.08 & 0.61 & 0.89 & 0.997 \\
\hline $\mathrm{CD}$ & exp & $\mathrm{Cu}$, high & syn & $\mathrm{Cu}$, high & -1.863 & -2.71 & -1.02 & -6.95 & $<0.001$ \\
\hline
\end{tabular}

Notes: Types of stress analyzed are selective stress effects (SE; comparison of synthetic communities reflecting the community structure under control and stress conditions) and context-dependent stress effects (CD; comparison of stressed and synthetic communities of the same community structure). Communities (experimental [Exp] and synthetic [Syn]) and treatments (low [200 $\mu \mathrm{g} / \mathrm{L}]$ and high [500 $\mu \mathrm{g} / \mathrm{L}] \mathrm{atra}-$ zine $[\mathrm{Atr}]$ and copper $[\mathrm{Cu}]$ ) indicate which communities and treatments are compared. Est indicates the difference in EFA production between the compared treatments as estimated by generalized least squares models fitted to Box-Cox transformed EFA data; lwr and upr indicate the lower and upper confidence intervals of the estimated difference. The $z$ and $P$ values corrected for multiple comparisons by the single-step method are presented; values in boldface type are statistically significant. 


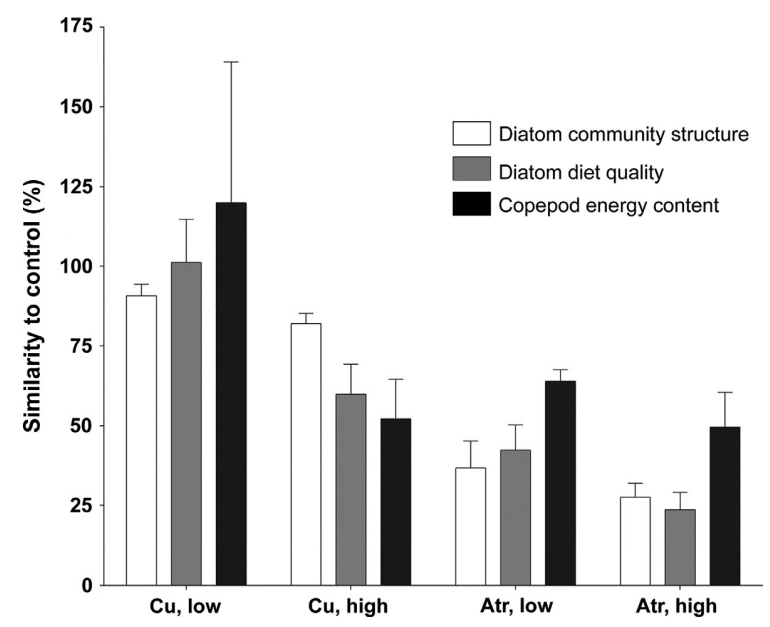

FIG. 3. Community structure and diet quality (EFA production per unit biomass) of diatom communities exposed to stress and EFA content of Microarthridion littorale after $10 \mathrm{~d}$ of feeding on the respective diets, visualized as percent similarity to the corresponding control. The similarity of diatom community structure is calculated as the Bray-Curtis similarity to the control mean (see Methods). The similarity of diatom and copepod EFA content is calculated as fraction percentage of the EFA concentration in treatment $i$ and the mean $(\mu)$ EFA concentration in the corresponding control c: $\left(\mathrm{EFA}_{i} / \mu \mathrm{EFA}_{\mathrm{C}}\right) \times 100$. Diatom communities were exposed to low $(200 \mu \mathrm{g} / \mathrm{L})$ and high $(500 \mu \mathrm{g} / \mathrm{L})$ atrazine (Atr) and copper $(\mathrm{Cu})$ concentrations, copepods were not exposed to any of the stressors. Values are means and bars are the standard deviation.

copepods also lost half of their EFA content, which was predicted not only by the diatoms' EFA content, but also by the changes in diatom community structure (Fig. 3, Table 3). Appendix S1: Fig. S3 shows the EFA content per diatom biomass and per copepod individual, as well as the relative proportion of eicosapentaenoic acid (EPA) and docosahexaenoic acid (DHA). In diatoms, the essential fatty acids consisted mainly of EPA, whereas DHA was the main component in copepods (EPA: DHA ratio 4-6 in diatoms, 0.3-0.6 in copepods; Appendix S1: Fig. S3). The copepod survival rate in the experimental units was between $85 \%$ and $100 \%$. The EFA content of copepods feeding on diatoms from control conditions $(65.3 \pm 6.1 \mathrm{ng} /$ copepod [mean \pm standard deviation]) did not differ significantly from copepods at the start of the experiment (i.e., animals collected in the field, $68.8 \pm 11.8 \mathrm{ng} /$ copepod, $t$ test, $P=0.99$, Appendix S1: Fig. S3).

\section{Discussion}

Biomass production is the most widespread functional endpoint in research on ecosystem functioning under anthropogenic change, and producer biomass (diet quantity) has been the main focus in most trophic experiments (Arts and Wainmann 1999, Balvanera et al. 2006, Cardinale et al. 2011). The loss of diatom biomass induced by copper corresponds to previous findings on the toxicity of copper to marine diatoms (Pistocchi et al. 1997, Masmoudi et al. 2013). Diatom biomass was not affected at low atrazine concentrations, although atrazine has been shown to reduce diatom biomass at concentrations lower than those used in our study (DeLorenzo et al. 1999, 2001, Magnusson et al. 2008). The capacity of our experimental diatom communities to maintain their biomass under low atrazine exposure was related to a change in community structure, with $C$. closterium becoming dominant in all atrazine-stressed communities. Atrazine blocks the electron transport chain of Photosystem II (PSII; Dorigo and Leboulanger 2001). Some diatom species can however reduce their dependency on photosynthesis and thus their sensitivity to PSII inhibitors by mixotrophic growth (i.e., the uptake of organic substrates; Debenest et al. 2009, Larras et al. 2014). C. closterium is capable of mixotrophic growth (Vanelslander et al. 2009), which reduces its sensitivity to herbicide stress (Mensens et al. 2017). The

TABLE 3. Results of generalized least squared models predicting copepod EFA content from diet quality (diatom EFA production) and diatom community structure.

\begin{tabular}{|c|c|c|c|c|c|c|c|c|c|}
\hline Stressor, predictor, and model & Slope & SE & $T$ & $P$ & AIC & Log likelihood & Validity & LR & $P \mathrm{LR}$ \\
\hline \multicolumn{10}{|l|}{ Atrazine } \\
\hline EFA & & & & & & & & 0.69 & 0.41 \\
\hline 1 & 0.059 & 0.008 & 7.38 & 0.0002 & 28.46 & -11.23 & yes & & \\
\hline 2 & 0.060 & 0.007 & 9.06 & $<0.0001$ & 29.77 & -10.89 & yes & & \\
\hline Comp & & & & & & & & 0.07 & 0.79 \\
\hline 1 & 0.045 & 0.008 & 5.88 & 0.0006 & 31.69 & -12.85 & yes & & \\
\hline 2 & 0.045 & 0.008 & 5.64 & 0.0008 & 33.62 & -12.81 & yes & & \\
\hline \multicolumn{10}{|l|}{ Copper } \\
\hline EFA & & & & & & & & 3.64 & 0.06 \\
\hline 1 & 0.137 & 0.021 & 6.57 & 0.0003 & 35.21 & -14.61 & yes & & \\
\hline 2 & 0.133 & 0.014 & 9.17 & $<0.0001$ & 33.57 & -12.79 & yes & & \\
\hline Comp & & & & & & & & 0.75 & 0.39 \\
\hline 1 & 0.204 & 0.126 & 1.62 & 0.1486 & 44.82 & -19.41 & no & & \\
\hline 2 & 0.071 & 0.150 & 0.48 & 0.6494 & 46.07 & -19.03 & yes & & \\
\hline
\end{tabular}

Notes: Copepods were offered a diet of diatom communities exposed to copper or to atrazine. Predictors are diet quality in terms of diatom community composition (Comp) or EFA production. Model indicates if the model was fitted without (Model 1) or with (Model 2) variance structure. Slope indicates the relation between predictors and copepod EFA content, i.e., the effect of diatom diet quality and community structure on copepod EFA content. SE is the standard error on the estimated slopes. The $t$ and $P$ values are presented; values in boldface type are statistically significant. AIC is the Akaike information criterion. Validity denotes if residuals were homogeneous and normally distributed or not (yes or no). If no, models were refitted (Model 2) with a variance structure allowing the residuals to change with the predictor. LR is the likelihood ratio of model 1 vs. model 2; $P$ LR the corresponding $P$ value. 
presence of a mixotrophic, atrazine-tolerant species thus caused changes in community structure that underpinned the absence of biomass loss at low atrazine levels.

Selective atrazine stress determined the diet quality of diatom communities, which lost $60 \%$ and $75 \%$ of their EFA content at low and high levels of the pesticide. The same extent of energy loss was observed in synthetic communities that reflected the community structure under atrazine without exposure to the pesticide. As diet quality in atrazineexposed experimental communities and unexposed synthetic communities did not differ, the energy loss under atrazine was caused by selective changes in community structure rather than by context-dependent atrazine effects on diatom diet quality. This selective atrazine stress could be attributed to the dominant species $C$. closterium, which produced three and eight times less EFAs than the species contributing the most biomass under control conditions, i.e., $N$. arenaria and $N$. acicularis, respectively (see fatty acids per species in Appendix S1: Table S1). In the presence of copper, communities were dominated by the same lipid-rich species as in the control, and as a result no selective effects on diet quality were observed. The lower diet quality in experimental compared to synthetic communities at high copper levels was therefore caused by context-dependent rather than selective copper effects. Context-dependent effects also likely caused the further loss of EFAs at high compared to low atrazine stress, since community structure at the two herbicide levels did not differ. This loss of diet quality at high levels of both stressors could be due to physiological stress effects such as an alteration of photosynthesis and thus of the carbon supply for fatty acid synthesis, inhibition of the enzymes involved in lipid biosynthesis or an increase in the degree of fatty acid saturation, which are all reported to reduce the microalgal EFA production under metal and pesticide stress (Böger et al. 2000, Guschina and Harwood 2006, Chia et al. 2013).

In our study system, selective stress proved to be the main driver of microalgal diet quality. Selective atrazine stress caused a more important loss of diatom diet quality than the context-dependent effects of both stressors, at chemical concentrations where no context-dependent effects on individual EFA content were recorded. It should however be highlighted that the levels of metal and pesticide stress used in this work are unlikely to occur in the diatoms' natural habitat. The atrazine and copper concentrations in this study can be representative of polluted estuaries in Asia and North America (Bai et al. 2011, Smith et al. 2012), but do not represent reported field concentrations in Europe (Janssen et al. 2010, Nödler et al. 2013), making chemical-stressinduced losses of diatom or copepod species in North Sea intertidal systems highly unlikely (Masmoudi et al. 2013, Wood et al. 2014). However, in this work chemical stress reduced ecosystem functioning mainly indirectly through shifts in community structure toward dominance by unproductive species rather than by directly affecting the species' numbers or their contribution to functioning. Such shifts in community structure can be induced by chemical concentrations lower than those used in this work (Debenest et al. 2010) and anthropogenic stressors are causing large-scale shifts in the composition of aquatic communities, with concomitant impacts on the functioning of aquatic food webs
(Hicks et al. 2011, McMahon et al. 2012, Litchman et al. 2015). Due to the pronounced differences in lipid profiles within and among algal classes (Taipale et al. 2013, Guo et al. 2016), these changes in community structure rather than direct stress effects on algal biochemical profiles could represent a potentially stronger driver of trophic energy flow under anthropogenic change.

The EFA content of the copepod M. littorale closely tracked that of its diet. Selective and context-dependent stress effects on diatom diet quality resulted in a concomitant loss in the EFA content of their main copepod grazer, confirming algal EFAs as being a key component of diet quality that is directly linked to trophic energy transfer. The DHA: EPA ratio of $M$. littorale was higher than in the diatom communities, which corresponds to previous findings on the relative concentrations of both EFAs in copepods and their algal diets (De Troch et al. 2012a, Arndt and Sommer 2014). Diatoms are characterized by a high EPA content (Taipale et al. 2013, Guo et al. 2016), but DHA appears to be the most important fatty acid for copepods (Taipale et al. 2013). Planktonic primary consumers such as cladocerans or calanoid copepods directly depend on the DHA taken up from their diet (Bell et al. 2007, Bell and Tocher 2009, De Troch et al. 2012a), but several harpacticoid copepod species are able to bioconvert EPA to the longer chain DHA, a capacity that has notably been demonstrated in M. littorale (De Troch et al. 2012a). While the total EFA content of M. littorale reflected that of its different diatom diets, this capacity to convert EPA to DHA likely enabled $M$. littorale to maintain high relative levels of DHA.

Our design of calculating synthetic communities from unstressed monocultures eliminated diversity effects such as species interactions, which can drive the functional contribution of communities along environmental gradients (Tylianakis et al. 2008a, Maestre et al. 2010). It should thus be noted that, while our experiments highlight potential functional impacts of selective stress, they do not allow to quantify diversity effects on diatom functioning. Our results also have to be treated carefully due to the limited number of stress levels and replicates. Also, offering M. littorale preserved rather than live diatom food might have influenced food uptake. Freeze-drying does not alter the biochemical composition within diatoms cells, but modifies the exterior of diatom cells through the loss of exudates or bacteria associated to the diatom frustule, which can affect the ingestion of diatoms by harpacticoid copepods (Cnudde et al. 2011). Feeding $M$. littorale live diatom cultures under unstressed conditions would however have resulted in a dissimilar diatom community structure than that induced by the stressors: atrazine and copper did not eliminate any of the diatom species, but caused alterations of community evenness, which typically cannot be maintained in the absence of the stressors (De Laender et al. 2016).

Since their EFA content ranks among the highest of all algae classes, diatoms are regarded as a high-quality food source and a crucial link for the energy flow at the basis of aquatic food webs (Guo et al. 2016). Here, diatom diet quality was more affected by chemical stress than by diet quantity. The selective and context-dependent stress effects on diatom diet quality were caused by the large interspecific differences in EFA content and the loss of diatom EFA 
content under stress. Indeed, the diet quality of benthic diatoms shows more interspecific variation and is more affected by chemical pollutants than their contribution to diet quantity (Mensens et al. 2015). Losses in diet quality occurred at copper concentrations that also impacted the survival of $M$. littorale when the copepods where directly exposed to copper (Appendix S1: Table S6). In addition to indirect effects on copepod EFA content through changes in diet quality, high metal stress can thus be expected to reduce copepod abundance through direct toxic effects. Conversely, atrazine changes microalgal community structure at concentrations lower than the $200 \mu \mathrm{g} / \mathrm{L}$ used in our study (Bérard and Benninghoff 2001, Debenest et al. 2010), whereas atrazine has been found to only acutely affect copepods at concentrations higher than $1 \mathrm{mg} / \mathrm{L}$ (Hall et al. 1995, Bejarano and Chandler 2003). Atrazine could thus first affect copepods indirectly through selective changes in the structure of their diatom diet rather than through direct effects on the copepods themselves.

The loss of diet quality did not result in increased harpacticoid mortality. Low diet quality rarely causes acute copepod mortality, but reduces copepod EFA content and, in the longer term, growth rate and reproduction (MüllerNavarra 1995, Müller-Navarra et al. 2000, Arendt et al. 2005, Gonçalves et al. 2011). The EFA content of copepods is crucial for their main consumers, especially larval fish whose development can depend on the EFAs taken up from their copepod prey (Sargent et al. 1995, Payne et al. 1998). While, in this study, losses in diet quality did not eliminate consumers, low diet quality could thus reduce the energy transfer at the plant-animal interface, which is a key limiting factor for the functioning of aquatic ecosystems (Brett and Müller-Navarra 1997, De Troch et al. 2012b). Nonetheless, the importance of algal diet quality, as distinct from just diet quantity, is rarely highlighted in research on food web functioning (Guo et al. 2016). Due to its sensitive response to selective stress, algal diet quality in terms of EFA production and community structure provides a powerful approach to integrate our understanding of coastal ecosystem functioning under anthropogenic change.

Our results support two conclusions. First, chemical stress differentially affects the contribution of marine primary producers to diet quantity and diet quality, with diet quality being more sensitive in this study. Second, selective stress caused a more important loss of diatom diet quality in our study system than context-dependent stress effects. Rather than variations in physiology, changes in community structure and differences in the diatoms' biochemical profiles thus represented the main driver of for energy flow to their copepod consumers. Moreover, it can be expected that the type of stress tested in this experiment will not only affect the copepod energy content, but also their growth and reproductive physiology. Therefore, the integration of diet quality into traditional studies of diet quantity is recommended to assess energy flow in marine food webs under anthropogenic change.

\section{ACKNOWLEDGMents}

The first author acknowledges the Doctoral Programme on Marine Ecosystem Health and Conservation (MARES) and the UGent Special Research Fund (BOF) for his doctoral research fellow grant.
The authors received additional financial support from the research council of Ghent University in the form of project BOF-GOA 01GO2617. The fatty acid analyses were performed by Dirk van Gansbeke and supported by FWO-Flanders in the form of the research grant $1523814 \mathrm{~N}$ awarded to the last author.

\section{Literature Cited}

Alheit, J., and W. Scheibel. 1982. Benthic harpacticoids as a food source for fish. Marine Biology 70:141-147.

Andersen, B. S., J. D. Carl, P. Grønkjær, and J. G. Støttrup. 2005. Feeding ecology and growth of age 0 year Platichthys flesus (L.) in a vegetated and a bare sand habitat in a nutrient rich fjord. Journal of Fish Biology 66:531-552.

Arendt, K. E., S. H. Jónasdóttir, P. J. Hansen, and S. Gärtner. 2005. Effects of dietary fatty acids on the reproductive success of the calanoid copepod Temora longicornis. Marine Biology 146: 513-530.

Arndt, C., and U. Sommer. 2014. Effect of algal species and concentration on development and fatty acid composition of two harpacticoid copepods, Tisbe sp. and Tachidius discipes, and a discussion about their suitability for marine fish larvae. Aquaculture Nutrition 20:44-59.

Arts, M. T., R. G. Ackman, and B. J. Holub. 2001. "Essential fatty acids" in aquatic ecosystems: a crucial link between diet and human health and evolution. Canadian Journal of Fisheries and Aquatic Sciences 58:122-137.

Arts, M. T., and B. C. Wainmann. 1999. Lipids in freshwater ecosystems. Springer, New York, New York, USA.

Bai, J., R. Xiao, B. Cui, K. Zhang, Q. Wang, X. Liu, H. Gao, and L. Huang. 2011. Assessment of heavy metal pollution in wetland soils from the young and old reclaimed regions in the Pearl River Estuary, South China. Environmental Pollution 159:817824.

Balvanera, P., A. B. Pfisterer, N. Buchmann, J.-S. He, T. Nakashizuka, D. Raffaelli, and B. Schmid. 2006. Quantifying the evidence for biodiversity effects on ecosystem functioning and services. Ecology Letters 9:1146-1156.

Bejarano, A. C., and G. T. Chandler. 2003. Reproductive and developmental effects of atrazine on the estuarine meiobenthic copepod Amphiascus tenuiremis. Environmental Toxicology and Chemistry 22:3009-3016.

Bell, M. V., J. R. Dick, T. R. Anderson, and D. W. Pond. 2007. Application of liposome and stable isotope tracer techniques to study polyunsaturated fatty acid biosynthesis in marine zooplankton. Journal of Plankton Research 29:417-422.

Bell, M., and D. R. Tocher. 2009. Biosynthesis of polyunsaturated fatty acids in aquatic ecosystems: general pathways and new directions. Pages 211-236 in M. Arts, M. Brett, and M. Kainz, editors. Lipids in aquatic ecosystems. Springer, Dordrecht, The Netherlands.

Benbrook, C. M. 2016. Trends in glyphosate herbicide use in the United States and globally. Environmental Sciences Europe 28:3.

Bérard, A., and C. Benninghoff. 2001. Pollution-induced community tolerance (PICT) and seasonal variations in the sensitivity of phytoplankton to atrazine in nanocosms. Chemosphere 45: 427-437.

Bianchini, A., S. E. G. Martins, and I. F. Barcarolli. 2004. Mechanism of acute copper toxicity in euryhaline crustaceans: implications for the Biotic Ligand Model. International Congress Series 1275:189-194

Böger, P., B. Matthes, and J. Schmalfuß. 2000. Towards the primary target of chloroacetamides-new findings pave the way. Pest Management Science 56:497-508.

Box, G. E. P., and D. R. Cox. 1964. An analysis of transformations (with discussion). Journal of the Royal Statistical Society B 26:211-252.

Brett, M. T., and D. C. Müller-Navarra. 1997. The role of highly unsaturated fatty acids in aquatic foodweb processes. Freshwater Biology 38:483-499. 
Buffan-Dubau, E., and K. R. Carman. 2000. Diel feeding behavior of meiofauna and their relationships with microalgal resources. Limnology and Oceanography 45:381-395.

Cardinale, B. J., K. L. Matulich, D. U. Hooper, J. E. Byrnes, E. Duffy, L. Gamfeldt, P. Balvanera, M. I. O'Connor, and A. Gonzalez. 2011. The functional role of producer diversity in ecosystems. American Journal of Botany 98:572-592.

Cardinale, B. J., et al. 2012. Biodiversity loss and its impact on humanity. Nature 486:59-67.

Chia, M. A., A. T. Lombardi, M. D. G. G. Melão, and C. C. Parrish. 2013. Effects of cadmium and nitrogen on lipid composition of Chlorella vulgaris (Trebouxiophyceae, Chlorophyta). European Journal of Phycology 48:1-11.

Clarke, K., and R. Gorley. 2006. PRIMER v6: user manual/tutorial. PRIMER-E, Plymouth, UK.

Cnudde, C., A. Willems, K. Van Hoorde, W. Vyverman, T. Moens, and M. De Troch. 2011. Effect of food preservation on the grazing behavior and on the gut flora of the harpacticoid copepod Paramphiascella fulvofasciata. Journal of Experimental Marine Biology and Ecology 407:63-69.

De Laender, F., et al. 2016. Re-introducing environmental change drivers in biodiversity-ecosystem functioning research. Trends in Ecology and Evolution 31:905-915.

De Troch, M., M. Grego, V. A. Chepurnov, and M. Vincx. 2007. Food patch size, food concentration and grazing efficiency of the harpacticoid Paramphiascella fulvofasciata (Crustacea, Copepoda). Journal of Experimental Marine Biology and Ecology 343:210-216

De Troch, M., M. B. Steinarsdóttir, V. Chepurnov, and E. Ólafsson. 2005. Grazing on diatoms by harpacticoid copepods: species-specific density-dependent uptake and microbial gardening. Aquatic Microbial Ecology 39:135-144.

De Troch, M., P. Boeckx, C. Cnudde, D. Van Gansbeke, A. Vanreusel, M. Vincx, and M. Caramujo. 2012a. Bioconversion of fatty acids at the basis of marine food webs: insights from a compound-specific stable isotope analysis. Marine Ecology Progress Series 465:53-67.

De Troch, M., I. Vergaerde, C. Cnudde, P. Vanormelingen, W. Vyverman, and M. Vincx. 2012b. The taste of diatoms: the role of diatom growth phase characteristics and associated bacteria for benthic copepod grazing. Aquatic Microbial Ecology 67:4758.

Debenest, T., E. Pinelli, M. Coste, J. Silvestre, N. Mazzella, C. Madigou, and F. Delmas. 2009. Sensitivity of freshwater periphytic diatoms to agricultural herbicides. Aquatic Toxicology 93:11-17.

Debenest, T., J. Silvestre, M. Coste, and E. Pinelli. 2010. Effects of pesticides on freshwater diatoms. Reviews of Environmental Contamination and Toxicology 203:87-103.

DeLorenzo, M. E., G. I. Scott, and P. E. Ross. 1999. Effects of the agricultural pesticides atrazine, deethylatrazine, endosulfan, and chlorpyrifos on an estuarine microbial food web. Environmental Toxicology and Chemistry 18:2824-2835.

DeLorenzo, M. E., G. I. Scott, and P. E. Ross. 2001. Toxicity of pesticides to aquatic microorganisms: a review. Environmental Toxicology and Chemistry 20:84-98.

D'Ippolito, G., A. Cutignano, R. Briante, F. Febbraio, G. Cimino, and A. Fontana. 2005. New C16 fatty-acid-based oxylipin pathway in the marine diatom Thalassiosira rotula. Organic \& Biomolecular Chemistry 3:4065-4070.

Dorigo, U., and C. Leboulanger. 2001. A pulse-amplitude modulated fluorescence-based method for assessing the effects of photosystem II herbicides on freshwater periphyton. Journal of Applied Phycology 13:509-515.

Fox, J. W. 2006. Using the price equation to partition the effects of biodiversity loss on ecosystem function. Ecology 87:2687-2696.

Fox, J. W., and W. S. Harpole. 2008. Revealing how species loss affects ecosystem function: the trait-based price equation partition. Ecology 89:269-279.
Gamfeldt, L., J. S. Lefcheck, J. E. K. Byrnes, B. J. Cardinale, J. E. Duffy, and J. N. Griffin. 2015. Marine biodiversity and ecosystem functioning: What's known and what's next? Oikos 124:252265.

Gonçalves, A. L., A. V. Lírio, J. Pratas, and C. Canhoto. 2011. Uranium contaminated water does not affect microbial activity but decreases feeding by the shredder Sericostoma vittatum. Fundamental and Applied Limnology/Archiv für Hydrobiologie 179:17-25.

Guillard, R. L. 1975. Culture of phytoplankton for feeding marine invertebrates. Pages 29-60 in W. Smith, and M. Chanley (Eds.), Culture of marine invertebrate animals SE - 3. Springer, New York City, New York, USA.

Guo, F., M. J. Kainz, F. Sheldon, and S. E. Bunn. 2016. The importance of high-quality algal food sources in stream food webscurrent status and future perspectives. Freshwater Biology 61:815-831.

Guschina, I. A., and J. L. Harwood. 2006. Lead and copper effects on lipid metabolism in cultured lichen photobionts with different phosphorus status. Phytochemistry 67:1731-1739.

Hall, L. W., M. C. Ziegenfuss, R. D. Anderson, and D. P. Tierney. 1995. The influence of salinity on the chronic toxicity of atrazine to an estuarine copepod: implications for development of an estuarine chronic criterion. Archives of Environmental Contamination and Toxicology 28:344-348.

Halpern, B. S., et al. 2008. A global map of human impact on marine ecosystems. Science 319:948-953.

Hänsch, R., and R. R. Mendel. 2009. Physiological functions of mineral micronutrients $(\mathrm{Cu}, \mathrm{Zn}, \mathrm{Mn}, \mathrm{Fe}, \mathrm{Ni}, \mathrm{Mo}, \mathrm{B}, \mathrm{Cl})$. Current Opinion in Plant Biology 12:259-266.

Hayes, T. B., et al. 2011. Demasculinization and feminization of male gonads by atrazine: consistent effects across vertebrate classes. Journal of Steroid Biochemistry and Molecular Biology 127:64-73.

Hicks, N., M. T. Bulling, M. Solan, D. Raffaelli, P. C. L. White, and D. M. Paterson. 2011. Impact of biodiversity-climate futures on primary production and metabolism in a model benthic estuarine system. BMC Ecology 11:7.

Hiddink, J. G., T. Wynter Davies, M. Perkins, M. Machairopoulou, and S. P. Neill. 2009. Context dependency of relationships between biodiversity and ecosystem functioning is different for multiple ecosystem functions. Oikos 118:1892-1900.

Hillebrand, H., C.-D. Dürselen, D. Kirschtel, U. Pollingher, and T. Zohary. 1999. Biovolume calculation for pelagic and benthic microalgae. Journal of Phycology 424:403-424.

Hillebrand, H., D. M. Bennett, and M. W. Cadotte. 2008. Consequences of dominance: a review of evenness effects on local and regional ecosystem processes. Ecology 89:1510-1520.

Hothorn, T., F. Bretz, and P. Westfall. 2008. Simultaneous inference in general parametric models. Biometrical Journal 50:346-363.

Janssen, C., P. Roose, H. De Brabander, M. Vincx, and J. Mees. 2010. Integrated risk assessment and monitoring of micropollutants in the Belgian coastal zone. INRAM. Final report phase 1. Belgian Science Policy, Brussels, Belgium.

Jodice, P. G. R., D. D. Roby, K. R. Turco, R. M. Suryan, D. B. Irons, J. F. Piatt, M. T. Shultz, D. G. Roseneau, A. B. Kettle, and J. A. Anthony. 2006. Assessing the nutritional stress hypothesis: relative influence of diet quantity and quality on seabird productivity. Marine Ecology Progress Series 325:267-279.

Knauert, S. 2008. Toxicity of pesticides and their mixture to primary producers. Dissertation. University of Basel, Basel, Switzerland.

Larras, F., V. Gregorio, A. Bouchez, B. Montuelle, and N. Chèvre. 2016. Comparison of specific versus literature species sensitivity distributions for herbicides risk assessment. Environmental Science and Pollution Research 23:3042-3052.

Larras, F., F. Keck, B. Montuelle, F. Rimet, and A. Bouchez. 2014. Linking diatom sensitivity to herbicides to phylogeny: A step forward for biomonitoring? Environmental Science \& Technology 48:1921-1930. 
Larsen, T. H., N. M. Williams, and C. Kremen. 2005. Extinction order and altered community structure rapidly disrupt ecosystem functioning. Ecology Letters 8:538-547.

Legrand, H., O. Herlory, J. M. Guarini, G. F. Blanchard, and P Richard. 2006. Inhibition of microphytobenthic photosynthesis by the herbicides atrazine and diuron. Cahiers de Biologie Marine 47:39-45.

Levy, J. L., J. L. Stauber, and D. F. Jolley. 2007. Sensitivity of marine microalgae to copper: the effect of biotic factors on copper adsorption and toxicity. Science of the Total Environment 387:141-154.

Litchman, E., P. de Tezanos Pinto, K. F. Edwards, C. A. Klausmeier, C. T. Kremer, and M. K. Thomas. 2015. Global biogeochemical impacts of phytoplankton: a trait-based perspective. Journal of Ecology 103:1384-1396.

Litzow, M. A., K. M. Bailey, F. G. Prahl and R. Heintz. 2006. Climate regime shifts and reorganization of fish communities: the essential fatty acid limitation hypothesis. Marine Ecology Progress Series 315:1-11.

Maestre, F. T., M. A. Bowker, C. Escolar, M. D. Puche, S. Soliveres, S. Maltez-Mouro, P. García-Palacios, A. P. Castillo-Monroy, I. Martínez, and A. Escudero. 2010. Do biotic interactions modulate ecosystem functioning along stress gradients? Insights from semi-arid plant and biological soil crust communities. Philosophical Transactions of the Royal Society B 365:2057-2070.

Magnusson, M., K. Heimann, and A. P. Negri. 2008. Comparative effects of herbicides on photosynthesis and growth of tropical estuarine microalgae. Marine Pollution Bulletin 56:1545-1552.

Manimaran, K., P. Karthikeyan, S. Ashokkumar, V. A. Prabu, and P. Sampathkumar. 2012. Effect of copper on growth and enzyme activities of marine diatom, Odontella mobiliensis. Bulletin of Environmental Contamination and Toxicology 88:30-37.

Masmoudi, S., N. Nguyen-Deroche, A. Caruso, H. Ayadi, A. Morant-Manceau, G. Tremblin, M. Bertrand, and B. Schoefs. 2013. Cadmium, copper, sodium and zinc effects on diatoms: from heaven to hell-a review. Cryptogamie, Algologie 34:185-225.

McMahon, T. A., N. T. Halstead, S. Johnson, T. R. Raffel, J. M. Romansic, P. W. Crumrine, and J. R. Rohr. 2012. Fungicideinduced declines of freshwater biodiversity modify ecosystem functions and services. Ecology Letters 15:714-722.

Mensens, C., F. De Laender, C. R. Janssen, K. Sabbe, and M. De Troch. 2015. Stressor-induced biodiversity gradients: revisiting biodiversity-ecosystem functioning relationships. Oikos 124:677-684.

Mensens, C., F. De Laender, C. R. Janssen, K. Sabbe, and M. De Troch. 2017. Different response-effect trait relationships underlie contrasting responses to two chemical stressors. Journal of Ecology 105:1598-1609.

Miralto, A., et al. 1999. The insidious effect of diatoms on copepod reproduction. Nature 402:173-176.

Müller-Navarra, D. C. 1995. Evidence that a highly unsaturated fatta acid limits Daphnia growth in nature. Archiv für Hydrobiologie 3:297-307.

Müller-Navarra, D. C., M. T. Brett, A. M. Liston, and C. R. Goldman. 2000. A highly unsaturated fatty acid predicts carbon transfer between primary producers and consumers. Nature 403:74-77.

Nödler, K., T. Licha, and D. Voutsa. 2013. Twenty years lateratrazine concentrations in selected coastal waters of the Mediterranean and the Baltic Sea. Marine Pollution Bulletin 70:112-118.

Noppe, H., A. Ghekiere, T. Verslycke, E. De Wulf, K. Verheyden, E. Monteyne, K. Polfliet, P. van Caeter, C. R. Janssen, and H. F. De Brabander. 2007. Distribution and ecotoxicity of chlorotriazines in the Scheldt Estuary (B-Nl). Environmental Pollution 147:668-676.

Österblom, H., O. Olsson, T. Blenckner, and R. W. Furness. 2008. Junk-food in marine ecosystems. Oikos 117:967-977.

Payne, M. F., R. J. Rippingale, and R. B. Longmore. 1998. Growth and survival of juvenile pipefish (Stigmatopora argus) fed live copepods with high and low HUFA content. Aquaculture 167:237-245.

Pennington, P., J. Daugomah, A. Colbert, M. Fulton, P. Key, B. Thompson, E. Strozier, and G. Scott. 2001. Analysis of pesticide runoff from mid-Texas estuaries and risk assessment implications for marine phytoplankton. Journal of Environmental Science and Health, Part B 36:1-14.

Pinheiro, J., D. Bates, S. DebRoy, D. Sarkar, and R Core Team. 2016. nlme: linear and nonlinear mixed effects models. https:// cran.r-project.org/web/packages/nlme/index.html (accessed 15 May 2018).

Pinho, G. L. L., M. S. Pedroso, S. C. Rodrigues, S. S. de Souza, and A. Bianchini. 2007. Physiological effects of copper in the euryhaline copepod Acartia tonsa: waterborne versus waterborne plus dietborne exposure. Aquatic Toxicology 84:62-70.

Pistocchi, R., F. Guerrini, V. Balboni, and L. Boni. 1997. Copper toxicity and carbohydrate production in the microalgae Cylindrotheca fusiformis and Gymnodinium sp. European Journal of Phycology 32:125-132.

R Development Core Team. 2016. R: a language and environment for statistical computing. R Foundation for Statistical Computing, Vienna, Austria.

Radchuk, V., F. De Laender, P. J. Van den Brink, and V. Grimm. 2016. Biodiversity and ecosystem functioning decoupled: invariant ecosystem functioning despite non-random reductions in consumer diversity. Oikos 125:424-433.

Raffaelli, D. 2006. Biodiversity and ecosystem functioning: issues of scale and trophic complexity. Marine Ecology Progress Series 311:285-294.

Real, M., I. Munoz, H. Guasch, E. Navarro, and S. Sabater. 2003. The effect of copper exposure on a simple aquatic food chain. Aquatic Toxicology 63:283-291.

Rhee, J. S., I. T. Yu, B. M. Kim, C. B. Jeong, K. W. Lee, M. J. Kim, S. J. Lee, G. S. Park, and J. S. Lee. 2013. Copper induces apoptotic cell death through reactive oxygen species-triggered oxidative stress in the intertidal copepod Tigriopus japonicus. Aquatic Toxicology 132-133:182-189.

Rohr, J. R., and P. W. Crumrine. 2005. Effects of an herbicide and an insecticide on pond community structure and processes. Ecological Applications 15:1135-1147.

Sanpera-Calbet, I., I. Ylla, A. M. Romaní, S. Sabater, and I. Muñoz. 2017. Biochemical quality of basal resources in a forested stream: effects of nutrient enrichment. Aquatic Sciences, 79, 99112.

Sargent, J. R., J. G. Bell, M. V. Bell, R. J. Henderson, and D. R. Tocher. 1995. Requirement criteria for essential fatty acids. Journal of Applied Ichthyology 11:183-198.

Schimel, J., T. C. Balser, and M. Wallenstein. 2007. Microbial stressresponse physiology and its implications for ecosystem function. Ecology 88:1386-1394.

Schneider, C. A., W. S. Rasband, and K. W. Eliceiri. 2012. NIH Image to ImageJ: 25 years of image analysis. Nature Methods 9:671-675.

Smith, R., R. Middlebrook, R. Turner, R. Huggins, S. Vardy, and M. Warne. 2012. Large-scale pesticide monitoring across Great Barrier Reef catchments-Paddock to Reef Integrated Monitoring, Modelling and Reporting Program. Marine Pollution Bulletin 65:117-127.

Taipale, S., U. Strandberg, E. Peltomaa, A. W. E. Galloway, A. Ojala, and M. T. Brett. 2013. Fatty acid composition as biomarkers of freshwater microalgae: analysis of 37 strains of microalgae in 22 genera and in seven classes. Aquatic Microbial Ecology 71:165-178.

Tylianakis, J. M., R. K. Didham, J. Bascompte, and D. A. Wardle. 2008a. Global change and species interactions in terrestrial ecosystems. Ecology Letters 11:1351-1363.

Tylianakis, J. M., T. A. Rand, A. Kahmen, A. M. Klein, N. Buchmann, J. Perner, and T. Tscharntke. 2008b. Resource heterogeneity moderates the biodiversity-function relationship in real world ecosystems. PLoS Biology 6:0947-0956.

Vanelslander, B., A. De Wever, N. Van Oostende, P. Kaewnuratchadasorn, P. Vanormelingen, F. Hendrickx, K. Sabbe, and W. Vyverman. 2009. Complementarity effects drive positive diversity 
effects on biomass production in experimental benthic diatom biofilms. Journal of Ecology 97:1075-1082.

von Elert, E. 2002. Determination of limiting polyunsaturated fatty acids in Daphnia galeata using a new method to enrich food algae with single fatty acids. Limnology and Oceanography 47:1764-1773.

Venables, W. N., and B. D. Ripley. 2002. Modern applied statistics with S. Springer, Berlin, Germany.

Wittebolle, L., M. Marzorati, L. Clement, A. Balloi, D. Daffonchio, P. De Vos, K. Heylen, W. Verstraete, and N. Boon. 2009. Initial community evenness favours functionality under selective stress. Nature 458:623-626.

Wood, R. J., S. M. Mitrovic, and B. J. Kefford. 2014. Determining the relative sensitivity of benthic diatoms to atrazine using rapid toxicity testing: a novel method. Science of the Total Environment 485-486C:421-427.

Zupo, V., T. J. Alexander, and G. J. Edgar. 2017. Relating trophic resources to community structure: a predictive index of food availability. Royal Society Open Science 4:160515.

\section{SUPPORTING INFORMATION}

Additional supporting information may be found online at: http://onlinelibrary.wiley.com/doi/10.1002/eap.1737/full 